Dynamics of Income Distribution across Chinese Provinces During 1978-1998

\author{
Hong Li
}

School of Economics

Kingston University

Penrhyn Road

Kingston KT1 2EE

UK

Email: $\underline{\text { H.Li@ kingston.ac.uk }}$ 
Dynamics of Income Distribution across Chinese Provinces During 1978-1998

Abstract

This study attempts to examine the growth pattern of China's economy during 19781998 from the perspective of income distribution dynamics. Motivated by the model of dynamic distribution, a transition matrix is derived from a panel of ratios of provincial real incomes to national averages across 30 provinces over 1978-1998. The transition matrix is used not only to reveal the transitions of provinces between the states of income over time, but also to predict whether there is a tendency across provinces to converge in real income per worker in the long run. This study finds evidence of a slight reduction of income dispersion across Chinese provinces over 1978-1998. But the slight reduction of income dispersion is not strong enough for the provinces to converge to mean income. However, there is a strong tendency to converge across provinces within regions and it is evident that in the eastern region poor provinces caught up with rich ones over the period under study. The ergodic distribution indicates that there will not be a tendency to converge in real GDP per capita across provinces in the long run. 


\section{Dynamics of Income Distribution across Chinese Provinces During 1978-1998}

\section{Introduction}

Some previous studies, such as Jian, Sachs and Warner (1996), Chen and Fleisher (1996) and Li, Liu and Rebelo (1998), have tried to examine the pattern of China's economic growth during the reform period $1978-1995$ by a conventional methodology. The method basically consists of regressing the subsequent growth rate on the initial level of income and some other explanatory variables, such as physical and human capital investment, growth of labour and measures of openness. Once the coefficient on the initial level of income is negative and statistically significant, these studies claim that there is a tendency across provinces to converge in real income per capita. They generally found a convergence in real income across Chinese provinces during the period up to 1995 .

There are a few problems with this conventional methodology. If we plot provincial average growth of real GDP per worker over 1978-1995 against their initial levels of real GDP per worker of 1978 as in Figure 1, we do not observe any negative correlation between them. Figure 1 shows a wide dispersion of average growth rates for provinces with low initial income levels.

Regressing the growth on the initial levels of real GDP per capita controlling other variables has been accused of falling foul of the Galton's fallacy of regression towards mean. Appendix 1 shows that a negative cross-section regression coefficient on initial levels is in fact perfectly consistent with the absence of convergence. Furthermore, cross-section and panel data regressions only capture the behaviour of a conditional 
average. Taking means and standard deviations ${ }^{1}$ of the cross-section distributions will not reveal the nature of convergence either.

Figure 1 Average growth (1978-1995) vs. initial levels (1978) of real GDP per worker

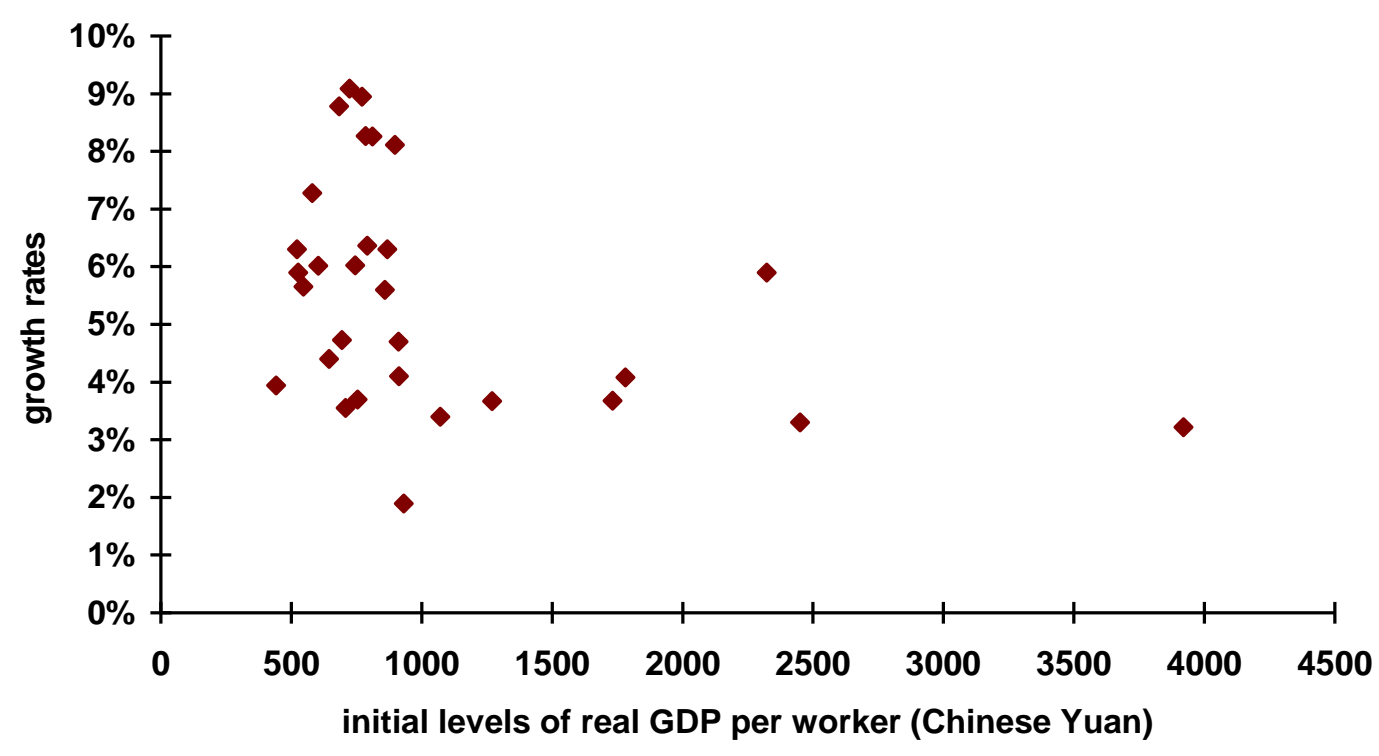

Quah (1993a) argues that convergence should concern about interactions across economies rather than whether a single economy is approaching its own individual steady state. Quah (1993a) proposes to use the model of dynamic distribution of income and discrete Markov chains to investigate the relative performance of rich and poor economies.

This paper will follow the line of Quah's study. It attempts to investigate the pattern of economic growth across Chinese provinces over 1978-1998 from the perspective of income distribution dynamics and answer the question which studies on convergence

\footnotetext{
${ }^{1}$ The other studies relevant to the test of convergence argue that if the dispersion--measured by the standard deviation of the logarithm of per capita income across a group of countries--declines over time, $\sigma$-convergence occurs.
} 
are concerned about: does growth in poorer economies lead to their catching up with the richer ones? Specifically, we will reveal the transitions of provinces between higher and lower income states over time and will examine whether the Chinese provinces converged in real income per worker over the period under study. We will also predict whether there is a tendency across provinces to converge towards the mean income in the long run.

The remainder of the paper is organised as follows. Section two presents the model of dynamic distributions. Section three applies Markov chains to the dynamics of crossprovince distribution of incomes in the case of China during 1978-1998. In section four we predict the long-run distributions of Chinese provincial income by the model of dynamic distributions. Section five investigates intra-regional dynamics. And Section 6 concludes.

\section{The model of dynamic distributions}

A theoretical model of distribution dynamics was originally developed by Loury (1981). Quah (1993a; 1996a, b) presents a few ways how distributions evolve. We choose the simplest law of motion to model distribution dynamics. Let $\mathrm{F}_{\mathrm{t}}$ denote the distribution of income across provinces at time $t$. Associated with each $F_{t}$ is a probability measure, $\mathrm{P}_{\mathrm{t}}$. Describe the evolution of $\left\{\mathrm{F}_{\mathrm{t}}\right.$ : integer $\left.\mathrm{t}\right\}$ by the law of motion:

$\mathrm{F}_{\mathrm{t}+1}=\mathrm{M} \cdot \mathrm{F}_{\mathrm{t}}$

where $\mathrm{M}$ is an operator mapping one distribution into another and tracks where in $\mathrm{F}_{\mathrm{t}+1}$ points in $\mathrm{F}_{\mathrm{t}}$ will end up. The operator works through providing predictions on how $\mathrm{P}_{\mathrm{t}}$ evolves over time, $\mathrm{P}_{\mathrm{t}+1}=\mathrm{M}\left(\mathrm{P}_{\mathrm{t}}\right)$. Equation (1) is useful in analysing dynamics in $\left\{\mathrm{F}_{\mathrm{t}}\right\}$. Iteration predicts future cross-section distributions. 
Taking equation (2) to the limit as $s \rightarrow \propto$, we can predict the likely long-run distribution of cross-province income. Convergence might be implied in $\left\{\mathrm{F}_{\mathrm{t}+\mathrm{s}}\right\}$ when the distributions tend to cluster around a point, while divergence into the poor and the rich might be indicated in $\left\{\mathrm{F}_{\mathrm{t}+\mathrm{s}}\right\}$ when the distributions tend towards a two-point distribution.

The model of dynamic distributions draws attention towards the cross-section interactions by providing an entire picture of how economies move between income states. The process how the entire cross section distribution evolves may be more indicative than the study of behaviour of a single representative unit towards its steady state by the conventional methodology.

\section{Empirical application of the model}

The model of dynamic distributions presents the mechanism that determines the relative performance of rich and poor economies. The mechanism can be approximated and estimated by discrete Markov chains (see Quah, 1993a, b; 1996a). Specifically, we will discretise the probability measures, $\mathrm{P}$, and derive a transition matrix to approximate the operator, $\mathrm{M}$, which is simply a law of motion for the evolving distributions.

Because the entire country has been growing during the period under study, we use relative income, the ratio of provincial real GDP per worker to national average real GDP per worker, as our basic data to eliminate this countrywide co-movement. Our 
data on real GDP per worker cover 30 provinces $^{2}$ over 1978-1998. Provincial real GDP per worker is derived as follows. Provincial GDP at current price is deflated with provincial retail price index and the deflated provincial GDP is divided by provincial working age population. Since Tibet does not have its provincial retail price index, we use the country's average retail price index to deflate its GDP series. In the Chinese statistics, gross domestic product (GDP) is defined in the same way as in the west. The retail price index by province is compiled by using the same list of products to calculate such an index for each province.

Our basic data, a panel of ratios of provincial real GDP per worker to national averages over 1978 - 1998, can have values ranging between 0 and infinity. We discretise the set of possible values of relative incomes into five states: $0-0.5,0.5-0.85,0.85-1.15,1.15-$ 1.5 and $>1.5$, with $0.85-1.15$ being the middle-income state. We then divide the provinces according to their provincial relative incomes of 1978 into five groups. This division shows each province's initial state of development accordingly.

Over 1978-1998, there are 20 observed one-year transitions over every year from 1978-1979 through 1997-1998 for each province. We calculate the probabilities of the provinces in each group to remain in the same state, to go ahead to higher states and to drop to lower states respectively. We assume that the matrix $M$ is time-invariant so that the probabilities can be estimated by averaging the observed one-year transitions over every year from 1978-1979 through 1997-1998 as Markov chain approach instructs. Basically, we use

$$
P_{i j}=n_{i j} / \sum_{j=1}^{5} n_{i j}
$$

\footnotetext{
2 Administratively there were not 31 provinces until 1997 when Chongqin City was separated from Sichuan Province to be an independent province. We stick to 30 provinces throughout this study. For data of 1997 and 1998, we simply add data on Chongqin to those on Sichuan in the yearbooks.
} 
which is the ratio of number of transitions $\left(n_{i j}\right)$ from state $i$ to state $j$ to the total number of times that all of the provinces were in state i prior to transition. Then, we place the probabilities in a $5 \times 5$ matrix, such that

$\sum_{j=1}^{5} P_{i j}=1$

for all $\mathrm{i}$.

All the relevant properties of $\mathrm{M}$ are then described by a $5 \times 5$ Markov chain transition matrix. The matrix $(i, j)$ entry is the probability that an economy in state $\mathrm{j}$ transits to state i. Low-numbered states correspond to low incomes: thus, for example, state 1 comprises income per worker no greater than half the country's average. This one-step annual transition matrix not only informs dynamics of income distributions, but also helps predict ergodic distribution.

\subsection{Dynamics of income distributions between states}

Table 1 One-step annual transition matrix from 1978-1979 through 1997-1998

\begin{tabular}{|l|l|l|l|l|l|}
\hline Obs. & $\begin{array}{l}\text { State 1 } \\
(0-0.5)\end{array}$ & $\begin{array}{l}\text { State 2 } \\
(0.5-0.85)\end{array}$ & $\begin{array}{l}\text { State 3 } \\
(0.85-1.15)\end{array}$ & $\begin{array}{l}\text { State 4 } \\
(1.15-1.5)\end{array}$ & $\begin{array}{l}\text { State 5 } \\
(>1.5)\end{array}$ \\
\hline 28 & $\mathbf{0 . 8 9 3}$ & 0.107 & & & \\
\hline 269 & 0.015 & $\mathbf{0 . 9 3 7}$ & 0.048 & & \\
\hline 162 & & 0.0555 & $\mathbf{0 . 8 8 9}$ & 0.0555 & \\
\hline 66 & & & 0.091 & $\mathbf{0 . 8 7 9}$ & 0.03 \\
\hline 75 & & & & 0.053 & $\mathbf{0 . 9 4 7}$ \\
\hline
\end{tabular}

Note: Values in the blank cells are zero. Off the first column, values in rows 2 to 6 are possibilities of transition across states over time.

Table 1 contains the one-step annual transition matrix, estimated by averaging the observed one-year transitions over every year from 1978-1979 through 1997-1998. The 
first column gives the total number of transitions with starting points in that income state. For example, the second row shows that over the entire sample - across 30 provinces and over 20 years - 269 observations fell in state 2, i.e., had incomes between half and 85 percent of the country's average. Of these observations, 93.7 percent remained in that same state in the following year while 4.8 percent moved to higher state and 1.5 percent dropped to lower state.

Over this one-year horizon the predominant feature is high persistence: all diagonal entries exceed 88 percent. It indicates that over 1978-1998 more than 88 percent of provinces remained in the same income states ${ }^{3}$. Casual observation readily comes up with examples of persistence. In 1998, some rich (the highest-income state) provinces, such as Beijing, Tianjin and Shanghai, have already been rich in 1978; similarly, a poor (the lowest-income state) province, Guizhou, has been poor in 1978. Guizhou stayed in the lowest-income state over the whole period under study.

However, this feature of persistence is relatively weak in comparison with Quah's (1993a) estimates for 118 countries over 1962-1985. Quah (1993a) estimates that the possibilities to remain are $0.97,0.92,0.92,0.94$ and 0.99 respectively for the five states from the lowest- to the highest-income. Correspondingly, the degree of mobility across states in our estimates is relatively higher.

Examples of the transitions are as follows. Two out of five rich provinces in 1978 have transited to being relatively poor. Liaoning dropped from the highest-income state to the upper middle-income state while Heilongjiang descended to the middle-income state in 1998. Meanwhile relatively poor provinces like Zhejiang, Fujian, Shandong and Guandong have transited to being relatively rich by leaping from the lower middle-

\footnotetext{
3 Persistence is corresponding to the national average income. In the period under study, the national average income kept increasing. Provinces persistent in any income state benefited from improvement in the standard of living during the period under study.
} 
income state in 1978 to upper middle-income state in 1998. With confidence we can say that the latter group (Zhejiang, Fujian, Shandong and Guandong) was catching up with Liaoning and overtaking Heilongjiang. Meanwhile, a group of provinces including Shanxi, Jiangsu, Gansu, Qinghai and Ningxia, beginning at the same level of development (the middle-income state) in 1978, eventually diverged. Whereas Jiangsu moved to the upper middle-income state, Shanxi, Gansu, Qinghai and Ningxia fell to the lower middle-income in 1998.

Furthermore Table 1 also shows how provinces moved across states. For both extremes, the probability $(0.107)$ for the lowest-income provinces to improve is higher than that $(0.053)$ for the highest-income provinces to fall behind. The lower middleincome provinces are more likely to go ahead (0.048) than to fall behind (0.015) while the upper middle-income economies are more likely to fall behind (0.091) than to go ahead (0.03). For the middle-income provinces, the possibility (0.0555) to go ahead is the same as that to fall behind.

The relatively higher degree of mobility and the feature of transition across states seem to be favourable for the reduction of uneven dispersions of provinces across states generally. However, the difference between our estimated highest and lowest possibilities to remain in their respective (same) states is almost as large as Quah's estimate of 7 percentage points, and our estimated two highest possibilities to remain are nearly as far apart across five income states as Quah's (1993a). In Quah's (1993a) study, across states, the possibilities to remain in the same states are much higher for two extremes, i.e., the highest- and lowest-income economies, than those for the middle-income economies. In our study, we found that the richest and lower middleincome provinces are more likely to remain than the rest. The similarity in the features of diagonal entries might have indicated a prediction of long run solution for the case of China similar to that for 118 economies by Quah (1993a, b). In the light of the distribution dynamics for 118 countries over 1962 - 1985, Quah (1993a, b) predicts 
that in the long run there will be a tendency to be 'twin peaks' in world income distribution, at low and high relative incomes. We will predict the long-run income distributions for the Chinese provinces in section 4.

\subsection{Income distributions over time}

To complete the description of these transition dynamics, we now consider the movement of income distributions over time (presented in Figure 2). The purpose of the consideration is to identify the shape, location and other external characteristics of the distributions at different time.

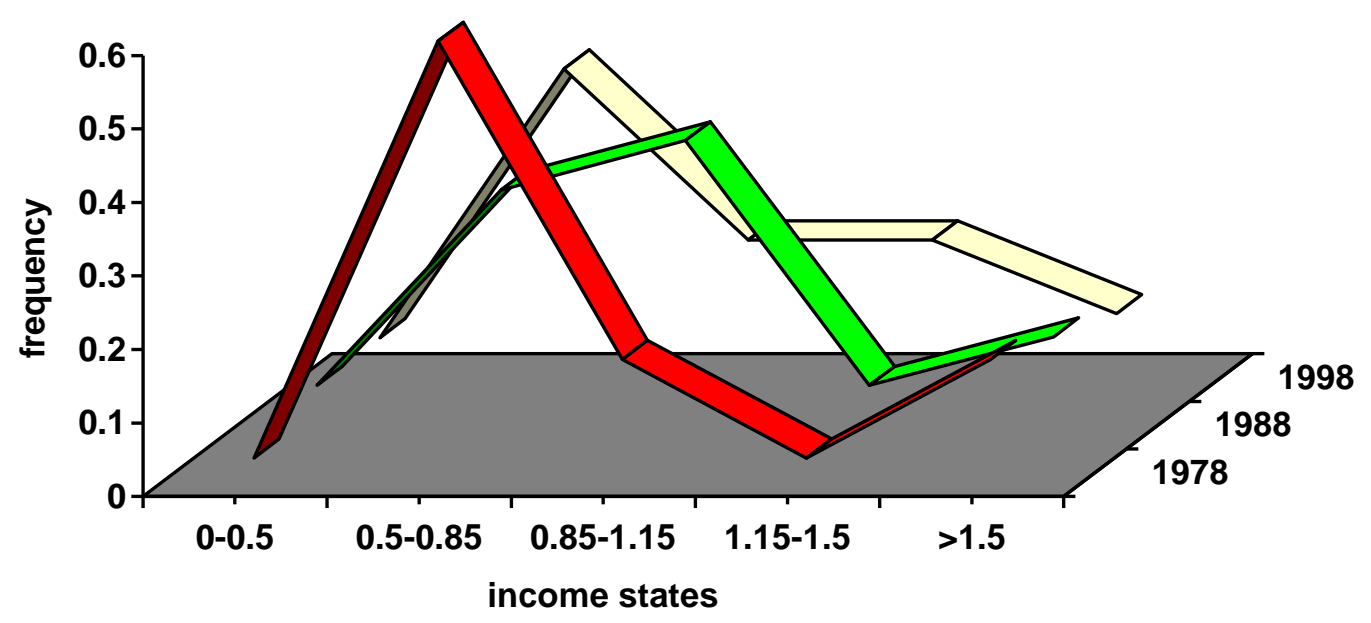

At a single glance, we notice that the yearly relative incomes of 1978 are unevenly dispersed, with only 16.7 percent of provinces clustering in the mean state. Among the 83.3 percent of provinces off the mean income, 60 percent of them clustered in the lower middle-income state in 1978. In the middle of the reform period, 1988, 40 percent of the provincial economies clustered in the middle income state. Thus the 
income distributions tended to converge to its mean during the first ten years of reforms. However, since 1988, the income distributions have tended to diverge. The income distribution of 1998 across provinces became unfavourable again as provinces dispersed across five income states. The density of mean state decreased while that of lower-middle-income and higher-middle-income states increased.

Thus it is evident that there was a changing tendency in the Chinese provincial income distributions during 1978-1998. The Chinese provincial economies tended to converge to mean income in the first 10 years whereas they tended to disperse across five income states with the highest density being in the lower middle-income state in the second 10 years. There is a slight reduction of income dispersions from 1978 to 1998 .

\section{Prediction of Long-run (ergodic) Income Distributions}

In section 3.1 we observed features both favourable and unfavourable to convergence of Chinese provincial real income in the long run, while we found a slight reduction of the income dispersion across provinces over 1978-1998 in section 3.2. It is of interest to see whether the features and slight reduction of income dispersion will lead to a tendency to converge in real GDP per worker in the long run. In other words, we like to derive the long run (or steady state) income distributions across provinces by using the transition matrix of Table 1. Markov process shows that the future set of proportions, the long-run income distributions across provinces in our case, is completely determined by the nature of the transition probabilities. The initial set of proportions has no effect on the long-run proportions. We estimate the long-run solution $\left(\pi_{\mathrm{i}}\right)$ implied in equation (2) by

$$
\pi^{\mathrm{T}}=\pi^{\mathrm{T}} \mathrm{P} \text { with } \sum_{i=1}^{5} \pi_{i}=1
$$


As $s \rightarrow \infty$, equation (2) estimates that the long-run income distributions are 0.0488 , $0.3518,0.306,0.187$ and 0.106 for states 1 to 5 respectively (Figure 3 and row 8 of Table 2). Only 30.6 percent of provinces will cluster around the middle-income state in the long run. The estimation implies that there will be unlikely a tendency to converge in real GDP per worker across Chinese provinces in the long run.

Table 2 State transitions 1978-1998 and ergodic distribution

\begin{tabular}{|l|l|l|l|l|l|}
\hline & $\underline{0-0.5}$ & $\underline{0.5-0.75}$ & $\underline{0.75-1}$ & $\underline{1-1.5}$ & $\underline{\geq 1.5}$ \\
\hline$\underline{0-0.5}$ & 25 & 3 & 0 & 0 & 0 \\
\hline$\underline{0.5-0.85}$ & 4 & 252 & 13 & 0 & 0 \\
\hline$\underline{0.85-1.15}$ & 0 & 9 & 144 & 9 & 0 \\
\hline$\underline{1.15-1.5}$ & 0 & 0 & 6 & 58 & 2 \\
\hline$\underline{\geq 1,5}$ & 0 & 0 & 0 & 4 & 71 \\
\hline Relative Means & 0.44 & 0.668 & 0.965 & 1.319 & 2.218 \\
\hline L-R Distribution & 0.0488 & 0.3518 & 0.306 & 0.187 & 0.1063 \\
\hline
\end{tabular}

Note: Values in rows 2 to 6 off column 1 are the number of transitions from state $i$ to state $\mathrm{j}$. All the states are relative to national averages.

Figure 3 Predicted long-run income distribution

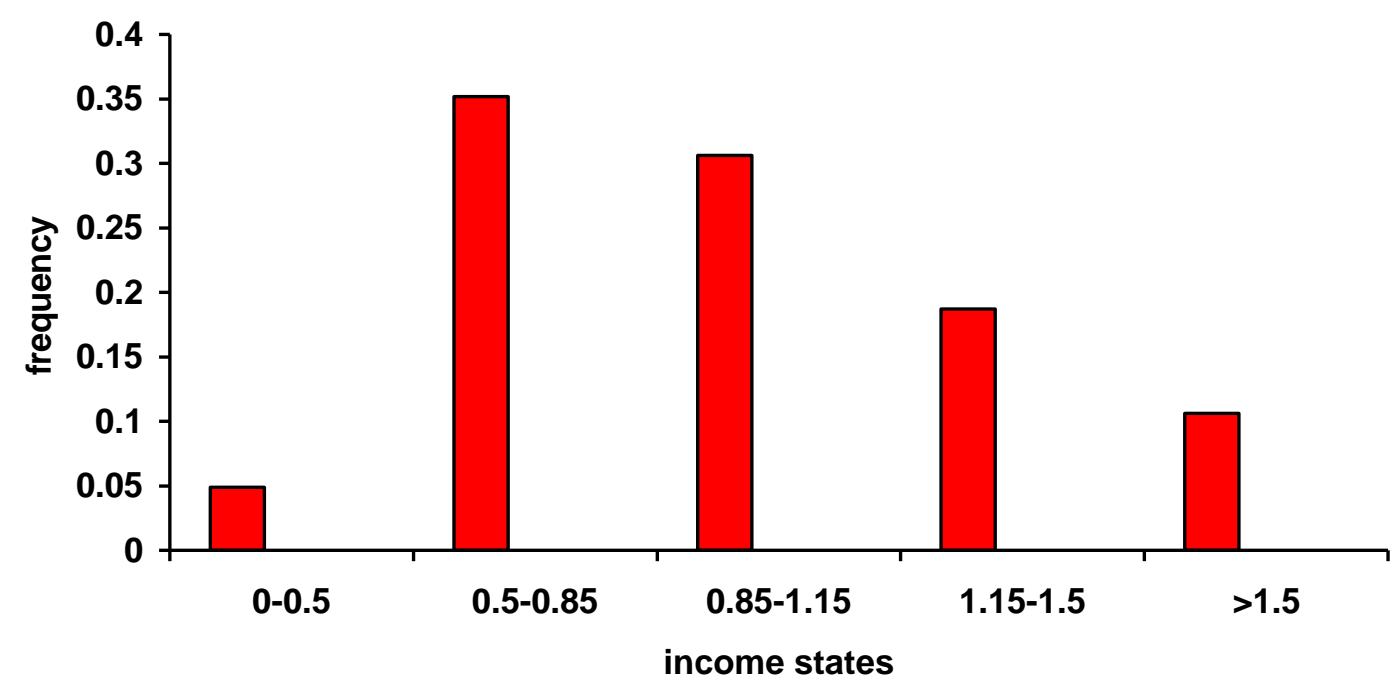


Our prediction that Chinese provinces tend to cluster off the mean state is justified to be mathematically and logically consistent ${ }^{4}$. Firstly, by definition, the mean of distribution is exactly one in state 3. By using the data on relative income within each state, we calculated the means of relative incomes within state i. They are $0.44,0.668$, $0.965,1.319$, and 2.218 respectively for $i=1,2, \ldots$ and 5 (presented in row 7 of table 2 ). The mean state in this study has a value of 0.965 , which is close to 1 .

Secondly, Pearlman (1998) emphasises the logical consistency of ergodic distribution as a constraint

$$
\sum_{i-1}^{5} \pi_{i} w_{i}=1
$$

where $\mathrm{w}_{\mathrm{i}}$ is mean of relative incomes within state $\mathrm{i}$. By summing up the product of the mean of relative income and the long-run distribution from state 1 to 5 , the long-run relative mean in our study is equal to 1.03 , which is a small bias from 1 .

\section{Income distributions conditional on geograhpy}

\subsection{Regional income distribution}

\footnotetext{
${ }^{4}$ We found a logical inconsistency in Quah's (1993a) methodology. If provinces in any one of the income states happen to be completely immobile, i.e. they do not move to other income states, the probability of staying in the immobile state will be 1 . Then when we use equations (2) and (4) to predict the ergodic or long-run income distributions, the estimate of the long-run income distribution for the completely immobile income state will be exactly 1 while the long-run income distributions will be zero for the other states between which provinces transit. This means that the immobile state appears to be an absorbing state. If the immobile state happens to be the lowest-income or highest-income state, there will be a contradiction. If all provinces end up in the lowest or highest-income state, the lowest or highest-income state should actually be the mean state. But the mean of the distribution is by definition the middle-income state, i.e. states 3, in this study. Pearlman (1998) proposes to resolve this inconsistency.
} 
In this section, we examine the dynamics within regions. China is a land of considerable regional variation in growth experience. During the period under study, the national average growth rate of real GDP per worker is 5.9 percent. However, provinces in the eastern region ${ }^{5}$ experienced an average growth rate of 6.87 percent while provinces in the central and western regions grew at the rates of 5.74 and 4.82 percent respectively over the period under study. It is of interest to see whether the difference in the rate of growth led to various patterns of within-region income distribution.

As Table 3 shows, in 1978, provinces of the eastern region were dispersed around the lower middle-income and highest-income states. Income inequality was evident in the beginning year of the reform period 1978-1998. In 1988, 5 out of 7 poor provinces moved ahead to the middle-income state. Until 1998, two thirds of poor provinces caught up with rich ones in the eastern regions and three quarters of the provinces in this region had real income higher than the national average. Provinces in the eastern region tended to converge in real GDP per worker in the upper middle-income state. Thus, during the period under study income inequality across Chinese eastern provinces steadily decreased.

In 1978, provinces in the central region spread from lower middle-income to highest income states, with two thirds of them having incomes lower than national average. In 1988, the spread of income distributions reduced to 3 states. During the year, the density of middle-income state increased to four ninths from a ninth in 1978 while that of lower middle-income state decreased to 4 ninths. In 1998, all the provinces across the central region clustered in either the lower middle-income or middle-income states.

\footnotetext{
${ }^{5}$ The Chinese provinces are divided into three regions geographically. The eastern, central and western regions, respectively, consisted of 12, 9 and 9 provinces till 1996. We keep this division throughout this study.
} 
During the period under study, provinces in the central region tended to converge in terms of real income per worker to the lower middle-income and middle-income states and income equality within the region also decreased.

The income distributions for the western regions are as follows: during the twenty years under investigation, the density of middle-income state decreased steadily while that of lower middle-income state increased. In 1978, two thirds of provinces in the western region had real incomes below the national average. In 1998, the density in the lower middle-income state increased to eight ninths of the provinces and provinces across the western region tended to converge in the real GDP per worker to the income below national average.

Table 3 Regional composition of states 1 to 5, 1978, 1988 and 1998

\begin{tabular}{|l|l|l|l|l|l|l|l|}
\hline & & $\begin{array}{l}\text { State 1 } \\
(0-0.5)\end{array}$ & $\begin{array}{l}\text { State 2 } \\
(0.5-0.85)\end{array}$ & $\begin{array}{l}\text { State 3 } \\
(0.85-1.15)\end{array}$ & $\begin{array}{l}\text { State 4 } \\
(1.15-1.5)\end{array}$ & $\begin{array}{l}\text { State 5 } \\
(>1.5)\end{array}$ & Total \\
\hline \multirow{4}{*}{ National } & 1978 & 1 & $\mathbf{1 8}$ & 5 & 1 & 5 & 30 \\
\cline { 2 - 8 } & 1988 & 2 & 10 & $\mathbf{1 2}$ & 2 & 4 & 30 \\
\cline { 2 - 8 } & 1998 & 2 & $\mathbf{1 3}$ & 6 & 6 & 3 & 30 \\
\hline \multirow{5}{*}{ Eastern } & 1978 & 0 & $\mathbf{7}$ & 1 & 0 & $\mathbf{4}$ & 12 \\
\cline { 2 - 9 } & 1988 & 1 & 2 & $\mathbf{6}$ & 0 & 4 & 12 \\
\cline { 2 - 8 } & 1998 & 1 & 1 & 1 & $\mathbf{6}$ & 3 & 12 \\
\hline \multirow{5}{*}{ Central } & 1978 & 0 & $\mathbf{6}$ & 1 & 1 & 1 & 9 \\
\cline { 2 - 8 } & 1988 & 0 & $\mathbf{4}$ & $\mathbf{4}$ & 1 & 0 & 9 \\
\cline { 2 - 8 } & 1998 & 0 & $\mathbf{5}$ & 4 & 0 & 0 & 9 \\
\hline \multirow{5}{*}{ Western } & 1978 & 1 & $\mathbf{5}$ & 3 & 0 & 0 & 9 \\
\cline { 2 - 8 } & 1988 & 1 & $\mathbf{5}$ & 2 & 1 & 0 & 9 \\
\cline { 2 - 8 } & 1998 & 1 & $\mathbf{7}$ & 1 & 0 & 0 & 9 \\
\hline
\end{tabular}

Note: Values off the first row and column are numbers of provinces. States 1 to 5 measures the provincial incomes relative to national averages.

Two features can be observed from the above regional distribution of incomes over time. First, it is evident that poor provinces caught up with rich ones in the eastern 
region over the period under study. Second, there is a strong tendency to converge in real GDP per worker across provinces within regions although particularly for the western region this is a convergence to an average well below the national one.

On the other hand, from the above regional income distributions over time, we can explain the national income distribution with a changing tendency during the period under study as follows. Firstly, five sevenths of the poor provinces in the eastern region and a third of the poor provinces in the central region moved to the middleincome state during the first 10 years. The strong tendency to move to mean income helped reduce the income dispersion across provinces in the first half of period under study. Secondly, five sixths of the middle-income provinces in the eastern region moved further ahead to the upper-middle-income state in the second 10 years while the provinces with income higher than national average in the central and western regions dropped to the middle-income, even lower middle-income states. The tendency to diverge led to uneven dispersion of provinces across states by the end of period under study.

\subsection{Income distribution conditional on geography}

This regional income distribution of 1998 seems to support the recent non-parametric work of Quah (1997). Quah (1997) shows that rich economies and poor economies respectively cluster geographically. To test this hypothesis, we apply Quah's (1997) methodology.

Basically, Quah (1997) takes ratios of a country's income relative to the average income of its physical neighbours and divides the ratios into the five original states as we did in section 3 . Then he plots a histogram of these income distributions against the five states of income relative to the world average in figure 7.1 of Quah (1997). The figure shows that for the higher-income and lower-income states, countries cluster 
around averages of their respective states although the probability of clustering is higher for the higher-income state than that for the lower-income one. Meanwhile for the middle income state countries spread evenly. This figure gives backing to the dynamic twin-peaks feature that rich countries are geographically close to other rich ones, and likewise poor countries are geographically close to each other. It appears that the polarisation he identified earlier in the unconditional distribution-dynamics of cross-country incomes is well explained by physical geography.

Accordingly, we take ratios of provincial income relative to neighbours' average and investigate the income distributions conditional on geography. Our results are presented in Table 4. States in the row are relative to national averages while those in the column are relative to neighbours' average. Like Quah (1997), we found that during the period under study, highest income provinces relative to national average (column 7) tended to cluster together geographically. The probability of clustering around the average of the state relative to neighbours' average increase from 0 (none out of five provinces) in 1978 to 0.333 (one out of three provinces) in 1998. It indicates that in 1978 rich provinces were dispersed, but they became closer geographically in 1998.

For the middle-income state, countries evenly spread geographically in Quah (1997). In the case of China, middle-income provinces also tended to disperse during the period under study as the probability of clustering around the average of the state relative to neighbours' average decreased from 0.4 to 0.333 . For the lower middleincome and upper middle-income states relative to national average, probabilities of clustering around their respective averages tended to decrease during 1978-1998 and the provinces tended to spread evenly.

However, we do not find any evidence that provinces with lowest income relative to national average clustered together by this approach. These provinces stayed isolated geographically in 1998, as the probability of clustering around the average of the state 
was again zero.

Table 4 Composition of states 1 to 5, 1978 and 1998, conditional on relative to neighbours' averages

\begin{tabular}{|l|l|l|l|l|l|l|}
\hline & & \multicolumn{5}{|c|}{ Relative to national average } \\
\hline & & $0-0.5$ & $0.5-0.85$ & $0.85-1.15$ & $1.15-1.5$ & $>1.5$ \\
\hline & Relative to neighbour's average & & & & & \\
\hline \multirow{5}{*}{1978} & State 1 & & 1 & & & \\
\cline { 2 - 8 } & State 2 & 1 & 5 & 1 & & \\
\cline { 2 - 8 } & State 3 & & $\mathbf{1 0}$ & $\mathbf{2}$ & $\mathbf{1}$ & \\
\cline { 2 - 8 } & State 4 & & & 2 & & 1 \\
\cline { 2 - 8 } & State 5 & 1 & 18 & 5 & 1 & 5 \\
\cline { 2 - 8 } & Total & & & & & \\
\hline 1998 & State 1 & 2 & 8 & 1 & 1 & \\
\cline { 2 - 8 } & State 2 & & $\mathbf{5}$ & $\mathbf{2}$ & $\mathbf{1}$ & $\mathbf{1}$ \\
\cline { 2 - 8 } & State 3 & & & 1 & 2 & \\
\cline { 2 - 8 } & State 4 & 2 & 13 & 6 & 6 & 3 \\
\cline { 2 - 7 } & State 5 & & & 2 & 2 & 2 \\
\cline { 2 - 7 } & Total & & & & & \\
\hline
\end{tabular}

Note: Values tabulated are the number of provinces.

After conditioning on geography, distributions of income over time are graphed in

Figure 4. It seems that income distribution spread evenly with probability peaking in the middle-income state only in 1978. During the year, our earlier unconditional income distributions could be explained by the geographic factor. Physical geography might have played an important role in cross-province income distribution before the reform period. However, geographical factor alone cannot explain the pattern of Chinese income distribution during the whole period under study as most provinces tended to locate off the mean state conditional on neighbours' average. Of course, when interpreting these results, we should bear in mind the fact that provinces locate closer to each other geographically than countries world-wide do to each other. 
Figure 4 Income distribution conditional on geography 1978, 1988 and 1998

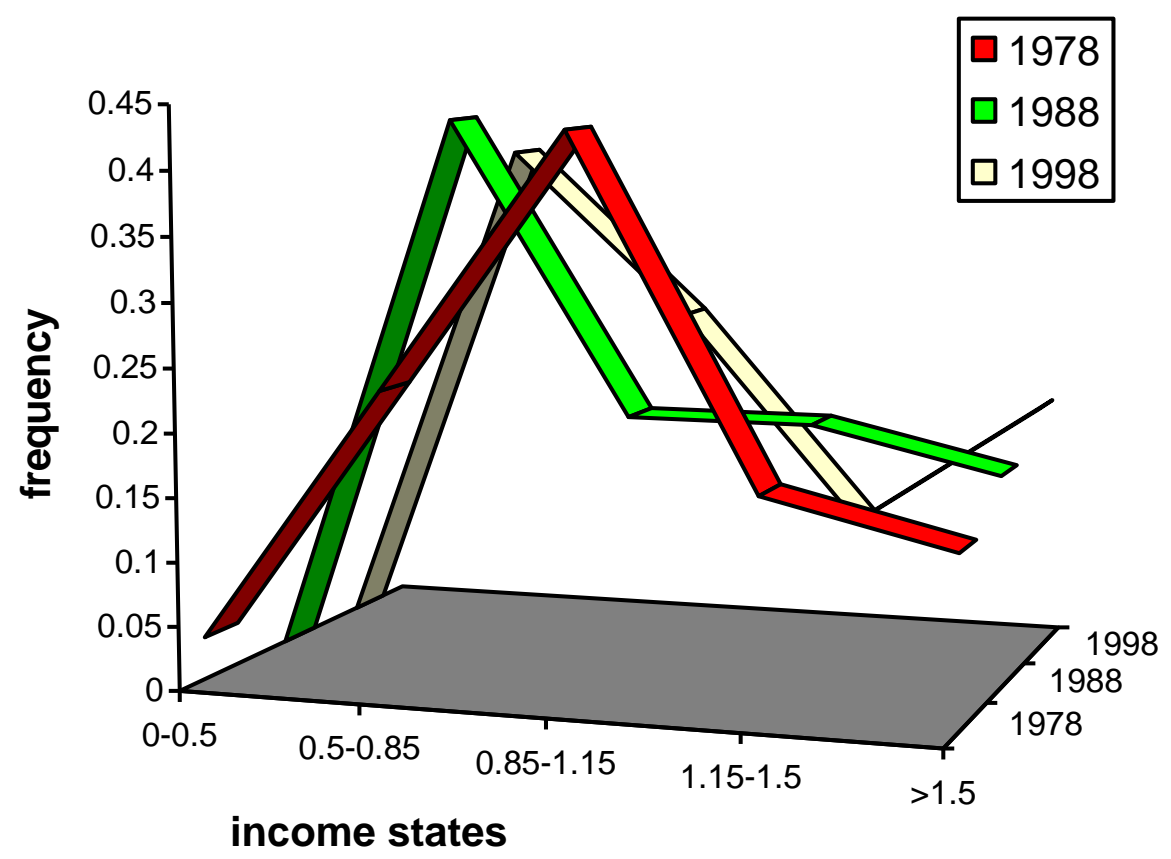

\section{Conclusion}

This paper has examined the pattern of economic growth across Chinese provinces from the perspective of distribution dynamics. It shows that income dispersion across provinces decreased slightly during 1978-1998 and predicts that there will hardly be any tendency to converge in the long run.

Meanwhile this study reveals the transitions between income states that have not been uncovered by the conventional methods of empirical analysis on China. By providing the entire picture of what happened with income across provinces, it demonstrates the relative performance across provinces between income states and over time. Comparing distributions in 1998 with those in 1978, 40 percent of provinces are persistent in income states while the rest are mobile. Divergence took place among some provinces that were in the middle-income state in 1978. While Jiangsu moved to 
the upper middle-income state, Shanxi, Gansu, Qinghai and Ningxia dropped to the lower middle-income state in 1995. However, convergence is also evident. Provinces in the central and western regions of China converged to the middle-income and lower middle-income states while provinces in the eastern region converged to the upper middle-income state in 1998. Provinces, like Zhejiang, Fujian, Shandong and Guangdong, even leapt to the upper middle-income state from the lower middleincome state.

The decomposition of income distribution into regional levels over time shows that rich provinces tend to cluster in the eastern region while poor ones locate in the western region. Furthermore, the investigation of income distributions conditional on neighbours' average incomes shows that provinces with middle and higher income tended to locate physically closer, but poor provinces, especially those with the lowest income, were isolated from each other geographically.

The advantage of the model of dynamic distributions is to provide an entire picture of what happened with income distributions across Chinese provinces over the period of 1978-1998. However, our prediction of the long-run income distributions is conditional on the arbitrary grid that was used to discretise the point-in-time empirical distributions. Moreover, this approach does not identify any variables likely to have influenced the pattern of Chinese economic growth during 1978-1998. 


\section{References:}

Chen, J., and Fleisher, B. M. (1996), 'Regional Income Inequality and Economic Growth in China', Journal of Comparative Economics, 22, 141-164

Jian, T., Sachs, J. D. and Warner, A. M. (1996), 'Trends in Regional Inequality in China', National Bureau of Economic Research Working Paper 5412

Li, H., Liu, Z. and Rebelo, I. (1998), 'Testing the Neo-classical Theory of Economic Growth: Evidence from Chinese Provinces', Economics of Planning 31:117-132

Loury, G. (1981), 'Intergenerational transfers and the distribution of earnings', Economica, 49 (4), 843-867

Pearlman, J. (1998), 'Twin Peaks - A Reassessment', European Economic Review (submitted)

Quah, D. (1993a), 'Empirical cross-section dynamics in economic growth', European Economic Review, 37(2/3), 426-434, April

Quah, D. (1993b), 'Galton's Fallacy and Tests of the Convergence Hypothesis', The Scandinavian Journal of Economics, 95 (4), 427-443

Quah, D. (1996a), 'Twin Peaks: Growth and convergence in models of distribution dynamics', Economic Journal, 106, 1045-1055, July

Quah, D. (1996b), 'Empirics for economic growth and convergence', European Economic Review, 40, 1353-1375

Quah, D. (1997), 'Empirics for Growth and Distribution: Stratification, Polarisation and Convergence Club', Journal of Economic Growth, 2(1), 27-59, March 


\section{Appendix 1 Galton's fallacy of regression towards mean}

To show the Galton's fallacy, we consider a regression model, $\mathrm{y}_{\mathrm{t} 0+\mathrm{T}, \mathrm{i}}=\alpha+\beta \mathrm{y}_{\mathrm{t} 0, \mathrm{i}}+\varepsilon_{\mathrm{i}}$. The OLS estimator for $\beta$ is

$\hat{\beta}=\frac{\sum\left(y_{t 0, i}-\bar{y}_{t 0}\right)\left(y_{t 0+T, i}-\bar{y}_{t 0+T}\right)}{\sum\left(y_{t 0, i}-\bar{y}_{t 0}\right)^{2}}$

Schwarz inequality says that

$\sum\left(y_{t 0, i}-\bar{y}_{t 0}\right)^{2} \sum\left(y_{t 0+T, i}-\bar{y}_{t 0+T}\right)^{2} \geq\left[\sum\left(y_{t 0, i}-\bar{y}_{t 0}\right)\left(y_{t 0+T, i}-\bar{y}_{t 0+T}\right)\right]^{2}$.

Suppose that $\left\{\mathrm{y}_{\mathrm{t} 0+\mathrm{T}}\right\}$ and $\left\{\mathrm{y}_{\mathrm{t} 0}\right\}$ have the same distribution, on average

$\sum\left(y_{t 0, i}-\bar{y}_{t 0}\right)^{2}=\sum\left(y_{t 0+T, i}-\bar{y}_{t 0+T}\right)^{2}$.

So $\sum\left(y_{t 0, i}-\bar{y}_{t 0}\right)^{2} \geq\left|\sum\left(y_{t 0, i}-\bar{y}_{t 0}\right)\left(y_{t 0+T, i}-\bar{y}_{t 0+T}\right)\right|$. Hence, $|\hat{\beta}|<1$.

Following Barro regressions, we take away the initial level of income, $\mathrm{y}_{\mathrm{t} 0, \mathrm{i}}$, from both sides of the regression model. The regression model became $\mathrm{y}_{\mathrm{t} 0+\mathrm{T}, \mathrm{i}}-\mathrm{y}_{\mathrm{t} 0, \mathrm{i}}=\alpha+(\beta-$

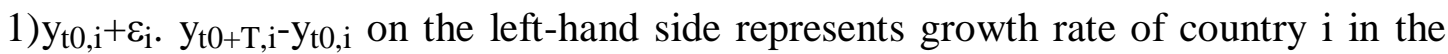
context of convergence. Because the estimator of $\beta$ is less than $1,(\beta-1)$ is nonpositive. Thus even if $\left\{\mathrm{y}_{\mathrm{t} 0+\mathrm{T}}\right\}$ and $\left\{\mathrm{y}_{\mathrm{t} 0}\right\}$ have the same distribution, i.e., there is no collapsing in distributions, the coefficient on the initial levels of income is negative. We can not judge whether there is a convergence from the negative coefficient on the initial levels of income. This, of course, is simply Galton's fallacy of regression towards the mean. 